\title{
Sezen Doğancı / Bir Sessiz Ölüm
}

\author{
Sezen Dŏgancı / A Silent Death
}

\section{Üstün Yıldırım"}

$\ddot{O}_{z}$

Türkiye'de üniversite kütüphaneciliğinin öncü isimlerinden değerli sınıf arkadaşım ve meslektaşım Sezen Doğancı'nın vefatı nedeniyle kaleme aldiğım anı yazısıdır.

Anahtar Sözcükler: Sezen Doğancl; Hacettepe Üniversitesi Tıp Merkezi Kütüphanesi; Ankara Üniversitesi Dil ve Tarih Coğrafya Fakültesi Kütüphanecilik Bölümü.

\begin{abstract}
This is the memoir I wrote due to the death of my dear classmate and colleague Sezen Doğancl, one of the pineers of university librarianship in Turkey.
\end{abstract}

Keywords: Sezen Doğancl; Hacettepe University Medical Center Library; Ankara University Faculty of Languages, History and Geography, Department of Librarianship.

Bir yazımda ölüm için şöyle demiştim:

“Ölüm yaşıtlarımı vurunca daha bir acıtır oldu yüreğimi. Stranın bana da gelmekte olduğu korkusundan belki de. 'Eyvah!' derim kendime 'daha altmışımı bile göremeden...' Oysa ne güzeldi 'Nereden gelirse gelsin, sefa geldi, hoş geldi' havasıla ölüme başkaldırmak."

Altmış yaşımda bile değilmişim ölümle cilveleştiğimde. Neredeyse üzerinden bir yirmi yı1 geçmiş. Seksenime doğru gidiyorum şimdilerde. Bu süreçte ölüm denilen o kaçınılmaz son bayağı bir acıttı yüreğimi. Çok yakınlarım, yakın uzak birçok tanıdı̆̆ım, yaşıtlarım birer birer bırakıp gittiler. Bunların ötesinde arkadaşım, sınıf arkadaşım, meslektaşım, çalışma arkadaşım çok kişi göçtü gitti bu dünyadan içimi acıtarak.

Yaşadığım o "sıranın bana da gelmekte olduğu korkusu" da kendiliğinden yok oldu. "Ha geldi, ha geliyor" beklentisine dönüştü artık iş.

Kimi zaman "gelse de gitsek artık" demeye bile götürdü. Kaçacak delik de olmadığına göre korkuyla yaşamanın ne anlamı olur ki. O beklenen son gelsin gelecekse, geleceği varsa göreceği de bir "hoş geldin" sözünden başka bir şey olmaz artık. "Niye böylesi geciktin?" demem umarım.

Ben korkuyu öldürdüm ya ölüm de korkumu canlandırmak; hem de körüklemek için döndü durdu yakın çevremde. Bildiğini de okudu, bilmediğini de. Giden gitti, kalanlara acı bırakarak.

\footnotetext{
*Emekli Kütüphaneci, E-Posta: oustunyildirim@gmail.com

Retired, E-Mail: oustunyildirim@gmail.com
}

Geliş Tarihi-Received: 30.11 .2021

Kabul Tarihi - Accepted: 04.12.2021

Yayımlanma Tarihi - Published: 30.12.2021 
Ahmet Gürlek gitti... Coşkun Saygı gitti... Adile Pehlivan gitti... Fatma Gümüş gitti... Leyla Turgut ve Rauf Arısoy da gitti. Hem sınıf arkadaşı, hem meslektaş, hem çalışma arkadaşı ve hem de arkadaştı bunlar. Yaşım gereği anımsayamadığım nice arkadaşlarım gitti... Haberim olmayan başka niceleri de... Korona salgının kol gezdiği yılların birinde, 2021 yılında da Sezen gitti... Sezen Doğancı... Aramızdan ayrılırken kullandığı adıyla Sezen Doğancı Tan.

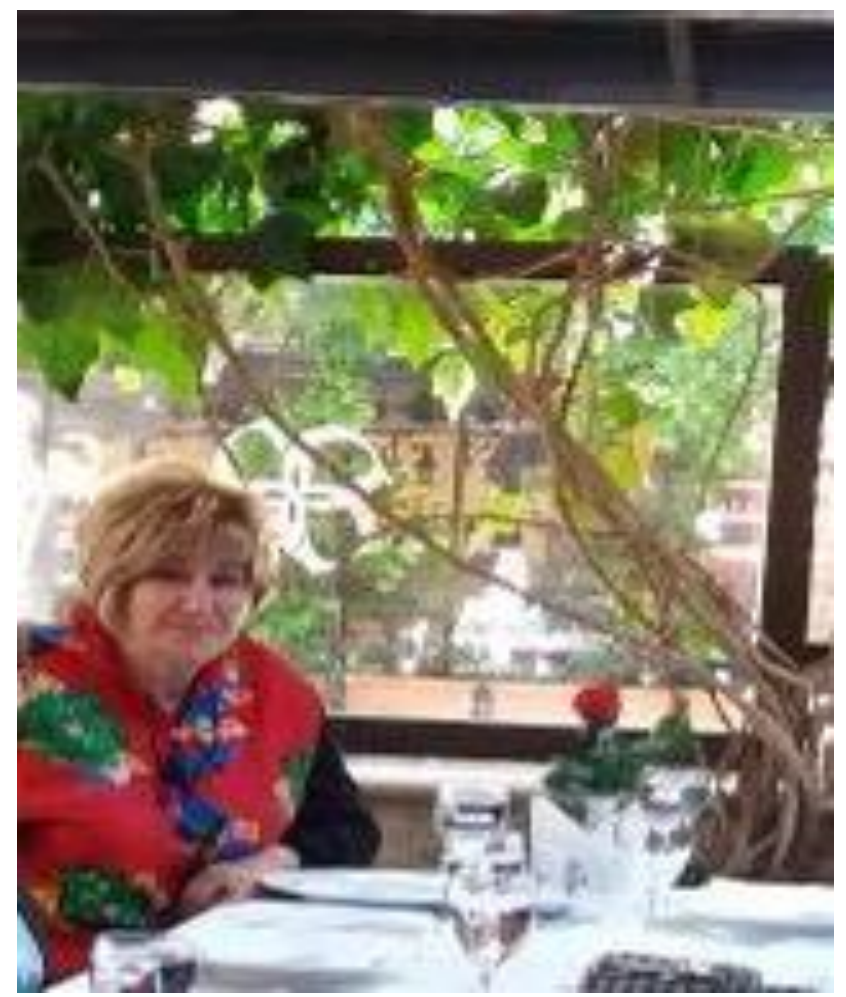

Görsel 1. Sezen Doğanc1 Tan. Böyle gülümsemişti yaşama...

Ben onu yaşama ayak bastığında edindiği adla, yani Sezen Doğancı olarak anacağım. Ben ve biz, yani sınıf arkadaşları öyle tanıdık onu 1964 yılının Kasım ayında. Sayın eşi, damadımız Yüksel Tan hoş görür umarım. Belki alışılageldiği gibi "enişte” demem gerekirdi; ama böyle bir yazıda ölümün kokusunu biraz olsun dağıtmak için "enişte” yerine "damat" demek geldi içimden. Sinıfımızdan kız alınmıştı ne de olsa.

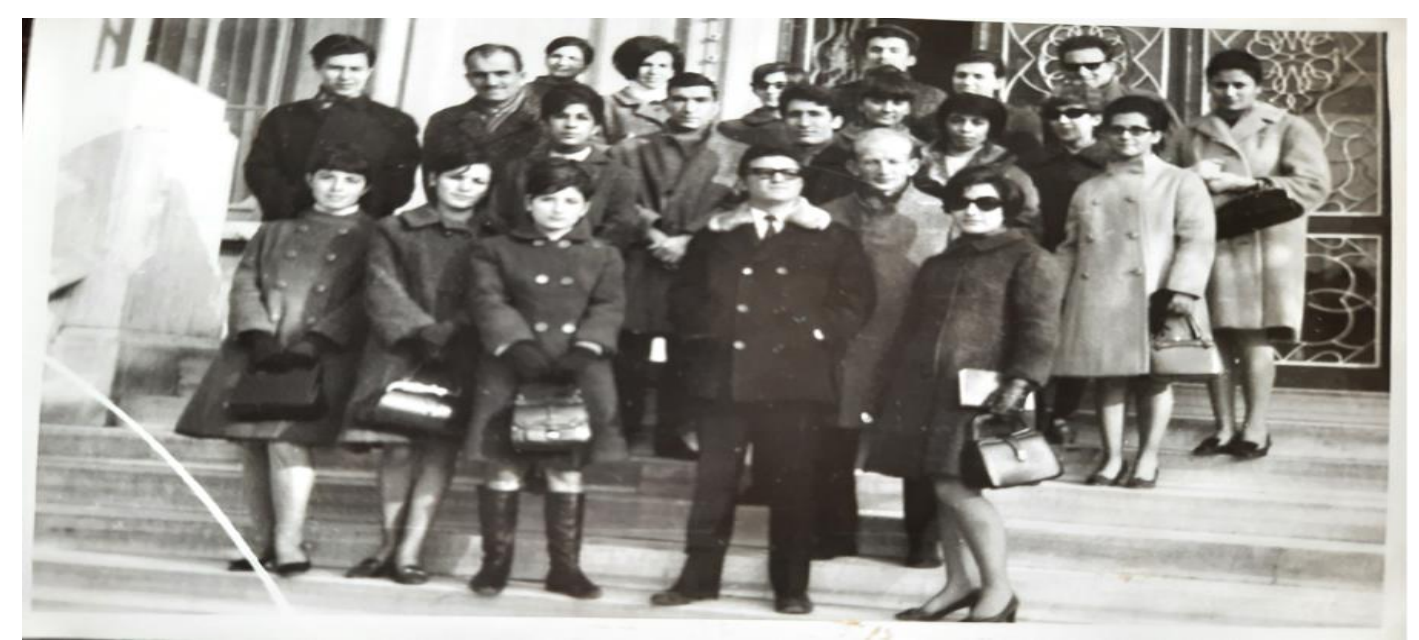

Görsel 2. Sınıf arkadaşlığımızın son yılları... Meslektaş olmanın az öncesinden siyah beyaz günler. 4 Şubat 1968. En arka sıranın sağ başında geleceğine bakar gibi... 
Dört yıl sınıf arkadaşı; onun bitiminden dört yıl sonra da çalışma arkadaşı olduk Sezen'le. Hacettepe Üniversitesi Kütüphanesi'ndeki bu arkadaşlığımız ben ayrılana dek sürdü. Altı yıl. O orada kaldı, Kütüphane Daire Başkanlığı'na dek yükseldi. Oradan da emekli oldu. Ama çok yıllar hep meslektaş, hep arkadaş olarak kaldık.

Sınıf arkadaşları olarak 50. yılımızdan başlayarak her yıl en az bir kez toplanmamızın esin kaynağı Sezen'dir aslında. İlk o toplamıştı bizi Hacettepe Üniversitesi Konukevi'nde. Ondan birkaç yıl sonra da düzenli toplanır olduk.

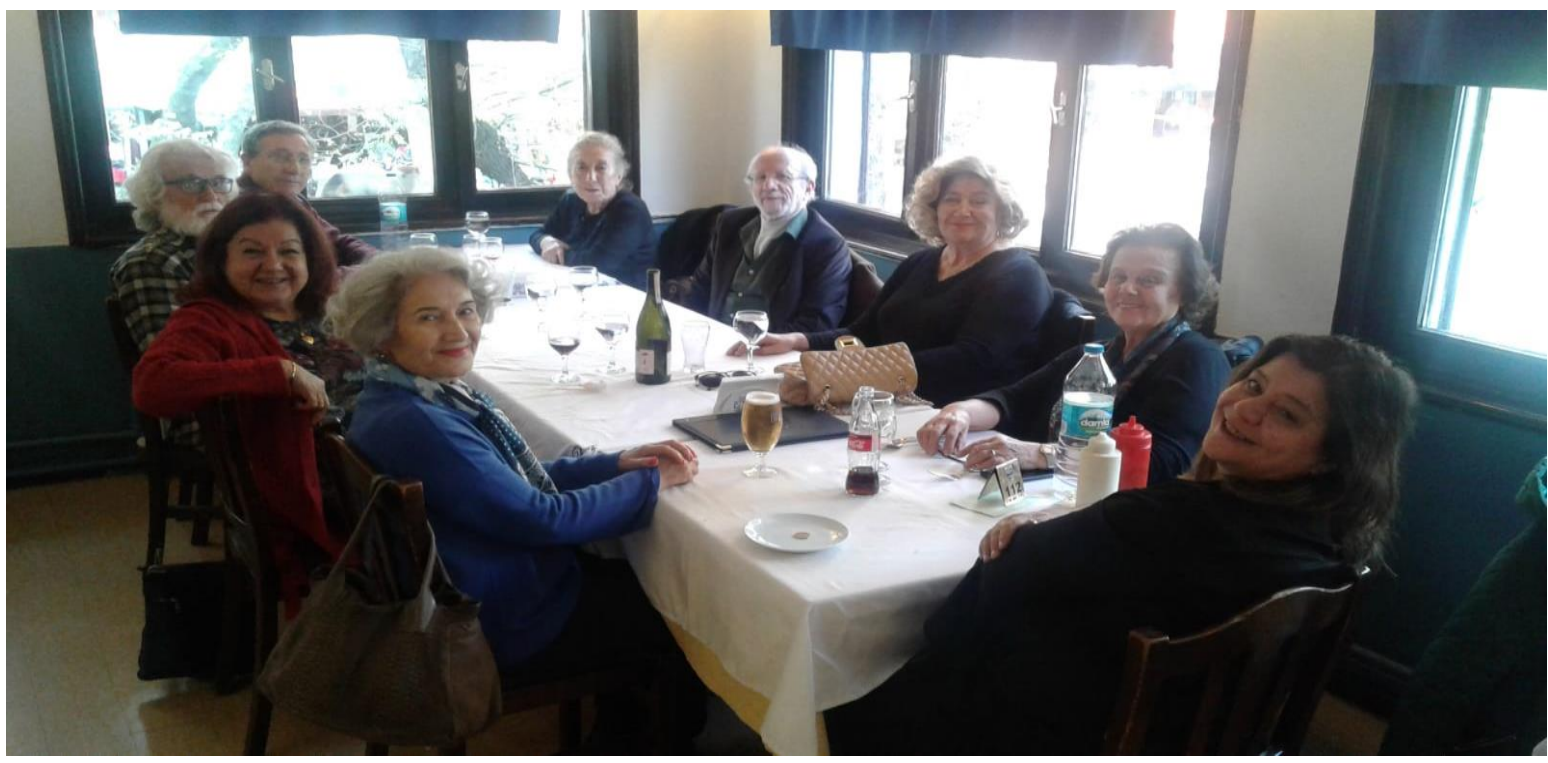

Görsel 3. İşte o toplantılardan birinde... Emekli meslektaşlar... Renklenmiş her şey...

Beklenmedik bir buluşma olmuştu Sezen'in düzenlediği toplantı. Çok sevinmiş, çok mutlu olmuştuk. Sezen böyle biriydi bana göre. Duruşuyla, bakışıyla, söyleyişiyle ve yaptıklarıyla sevindiriverirdi insanı. Ve o Sezen, yani benim gördüğüm Sezen az konuşan biriydi. Söyleyeceğini söyler, sözü uzatmak için kimi arayışlara girmezdi. Hep düşünür gibi bir duruşu vardı. Otururken, dinlerken, yürürken... Sanki düşünsel olarak daha etkin bir yapısı vardı. Tez canlıydı. İş bitiriciydi, çalışkandı. Çünkü o Sezen'di.

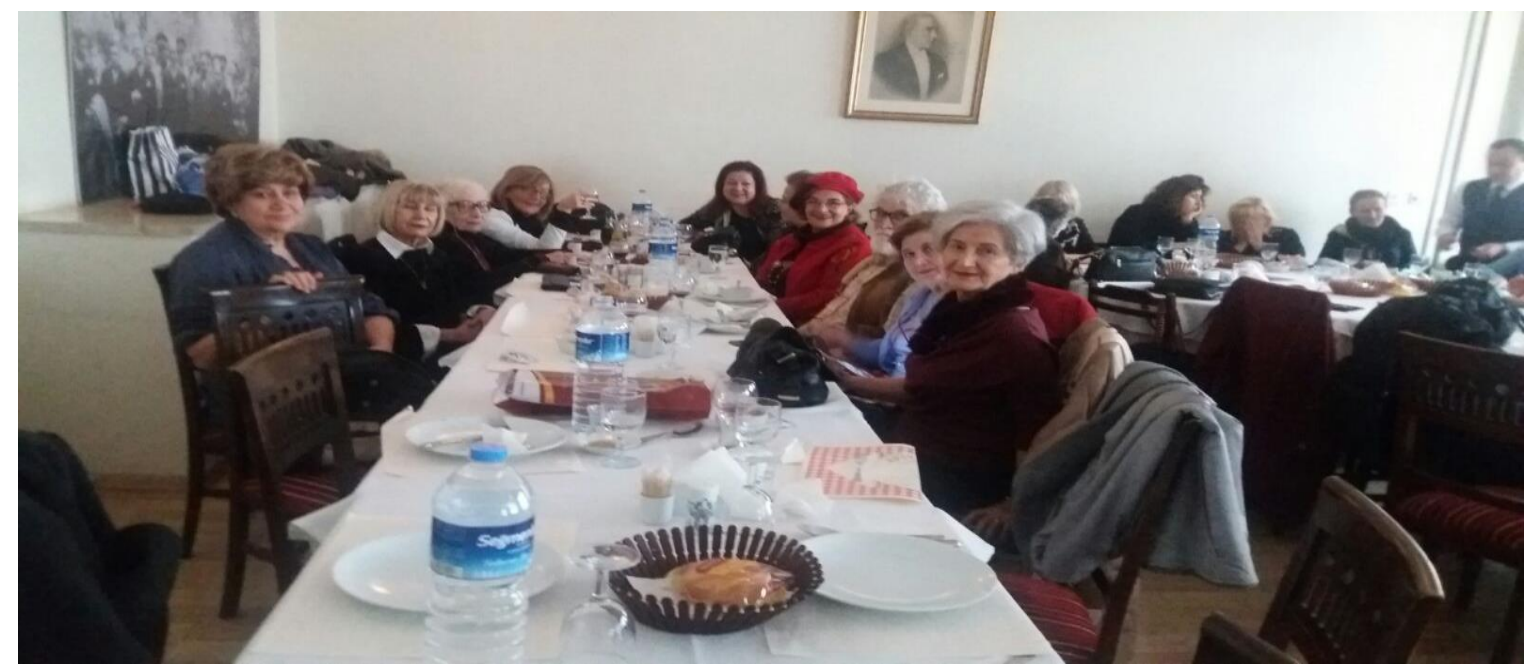

Görsel 4. Bir başka sınıf toplantısı... Prof. Dr. Berin U. Yurdadoğ ile... Yaşlılığımızın renkliliğindeyiz... 
İletişim olanaklarının gelişmesi ve çeşitlenmesi toplanmamızı engellemiyor, daha sık iletişim kurmamızı sağlıyordu. Sınıf arkadaşları olarak "68 Kuşağı (Sınıfdaşlar)” diye bir WhatsApp topluluğu oluşturduk. Orada daha sık toplanır ve yazışır olduk. Daha çok ve daha tez iletişim kuruyorduk böylece. Sezen, taşlara ilgimi bildiğinden, bulduğunda taştan yapılmış güzel sanat yapıtları gönderirdi bana, beni özendirmek için. En son 12 Nisan' da göndermiş bir resim. Sonra sesi çıkmadı. Kötüye yormadım, yoramazdım. Dedim ya Sezen'di bu ve az konuşurdu. Yine de şaka yollu seslenişlerim, çağırışlarım oldu. Bir arkadaşımızın uyarısı beni kendime getirdi. Kendime gelmiş miydim, yoksa daha mı kendimi yitirmiştim bilemiyorum. Sezen yanıt veremeyecek durumdaymış çünkü. Ve biz hepimiz yıkılmıştık. Hiç sözünü etmediği sayrılık yeniden ortaya çıkmıştı. Ve hiç de iyi değildi. Bir ölüm sessizliği düştü her yere. Sonra da o sessizliğin içine ölümün kendisi. 2021 yılının Ağustos ayında. Sezen de gitmişti...

Sessizce... 